José Augusto Pina ${ }^{1}$

Eduardo Navarro Stotz ${ }^{2}$

\section{Intensificação do trabalho e saúde do trabalhador: uma abordagem teórica}

\author{
Work intensification and workers' health: a theoretical approach
}

${ }^{1}$ Fundação Oswaldo Cruz, Escola Nacional de Saúde Pública Sergio Arouca, Centro de Estudos da Saúde do Trabalhador e Ecologia Humana. Rio de Janeiro, RJ, Brasil.

${ }^{2}$ Fundação Oswaldo Cruz, Escola Nacional de Saúde Pública Sergio Arouca, Departamento de Endemias Samuel Pessoa. Rio de Janeiro, RJ, Brasil.

Contato:

José Augusto Pina

E-mail:

augusto@ensp.fiocruz.br

Artigo elaborado com base na tese de doutorado de José Augusto Pina intitulada Intensificação do trabalho e saúde dos trabalhadores na indústria automobilística: estudo de caso na Mercedes Benz do Brasil, São Bernardo do Campo, defendida na Escola Nacional de Saúde Pública Sergio Arouca, Fundação Oswaldo Cruz, em 2012.

Trabalho não apresentado em reunião científica.

O trabalho não contou com financiamento.

Os autores declaram não haver conflitos de interesse.

\section{Resumo}

Objetivo: construir uma definição conceitual para o processo intensificação do trabalho e saúde do trabalhador enquanto um objeto de estudo. Métodos: a abordagem teórica baseia-se no materialismo histórico que, na Saúde Coletiva/ Saúde do Trabalhador, encontra sua expressão na determinação social do processo saúde-doença. A discussão se apoia na recente produção de conhecimento científico sobre essa problemática estruturada em dois eixos: intensificação do trabalho e intensificação do trabalho e saúde dos trabalhadores. Discussão: a análise mostrou que a intensificação do trabalho está implicada em práticas de exploração como o prolongamento da jornada, o intenso ritmo de trabalho e a administração por estresse e, ao mesmo tempo, de expropriação do saber do trabalhador pela gerência, isto é, de suas capacidades físicas, psíquicas e intelectuais. Esses processos determinam uma pluralidade de agravos à saúde e na manifestação do desgaste e do sofrimento difuso dos trabalhadores. Conceitualmente, o objeto intensificação do trabalho e saúde do trabalhador pode ser definido e estudado nas práticas específicas de exploração e expropriação do saber do trabalhador tendentes a enfraquecer sua capacidade coletiva para proteger a saúde e para questionar as determinações dos problemas e agravos à saúde.

Palavras-chave: intensificação do trabalho e saúde do trabalhador; Saúde do Trabalhador; administração por estresse; sofrimento difuso; penosidade no trabalho.

\begin{abstract}
Objective: to construct a conceptual definition of the work intensification process and workers' health as an object of study. Methods: the theoretical approach is based on the historical materialism, which, in the field of Collective Health/ Worker's Health, is expressed on the social determination of the health-disease process. The discussion is grounded on the recent scientific knowledge production on this issue, structured on two axes: work intensification, and work intensification and workers' health. Discussion: the analysis showed that labor intensification is associated with exploitation practices, such as longer working hours, intense work pace, management by stress and, at the same time, worker's knowledge expropriation by the management, i.e., expropriation of their physical, intellectual and psychic capabilities. These processes determine a variety of health problems and the manifestation of wearing down and diffuse suffering among workers. Conceptually, the object "work intensification and workers' health" can be defined and studied in the exploitation specific practices and worker's knowledge expropriation, tending to weaken their collective ability to protect health and question the determination of health problems.
\end{abstract}

Keywords: work intensification and workers' health; Workers' Health; management by stress; diffuse suffering; penibility at work. 


\section{Introdução}

O processo de intensificação do trabalho em curso nas últimas décadas é um fenômeno global, abrange inúmeras categorias profissionais, em diversos países e setores produtivos de bens e de serviços privados ou públicos. Como problemática contemporânea, a intensificação do trabalho e saúde do trabalhador emerge enquanto um problema científico das condições históricas do desenvolvimento capitalista, a partir da crise dos anos 1970, período em que as mudanças no processo de trabalho geraram uma acentuada piora das condições de trabalho vivenciadas pelos trabalhadores nos EUA e na Europa.

Nos EUA, o debate da intensificação do trabalho está relacionado à implantação na indústria do sistema Toyota de produção, criticamente denominado de Management by Stress - administração por estresse (PARKER; SLAUGHTER, 1995). O estresse emerge como instrumento gerencial para manter a pressão permanente sobre os operários e elevar a produtividade. Na Europa, o estudo da intensificação, inclusive apoiado nos inquéritos estatísticos sobre as condições de trabalho a partir da percepção dos trabalhadores, destaca múltiplos aspectos relacionados ao processo de trabalho, à organização sindical e à saúde dos trabalhadores (ASKENAZY et al., 2006).

No Brasil, intensificação do trabalho implicada na saúde do trabalhador ainda não constitui um objeto de estudo na Saúde Coletiva. Apenas mais recentemente essa questão emerge como um problema de pesquisa. Registram-se duas importantes iniciativas: o seminário "O processo de intensificação do trabalho sob diferentes olhares", organizado pela Fundação Jorge Duprat Figueiredo de Segurança e Medicina do Trabalho (Fundacentro), em maio de 2009, e a mesa redonda "Intensificação do trabalho e saúde", realizada pela Associação Brasileira de Estudos do Trabalho (ABET), em outubro de 2009.

Dado esse contexto, esta pesquisa tem por objetivo construir uma definição conceitual para o processo intensificação do trabalho e saúde do trabalhador enquanto objeto de estudo capaz de delimitar os contornos e os traços por meio dos quais esse objeto se expressa como dimensão particular do processo de trabalho e saúde.

\section{Método}

O quadro teórico-conceitual aqui apresentado sustenta-se no materialismo histórico que, na Saúde Coletiva, encontra sua expressão na determinação social do processo saúde-doença. Nossa exposição, na esteira de Marx (1984a), encaminha o pensamento na direção da maior complexidade, ou seja, a reflexão evolui da intensificação do trabalho situada no modo de produção capitalista (nível mais elevado de abstração ou das determinações mais gerais) para a intensificação do trabalho e saúde situada nos processos históricos reais de uma formação econômica social (nível mais baixo de abstração, com a incorporação de um número maior de determinações relativamente a um objeto de estudo).

A discussão se apoia na recente produção de conhecimento científico sobre essa problemática. Na literatura internacional tomamos como principal fonte os estudos apresentados no seminário (mensal) sobre intensificação do trabalho organizado pelo Centre d'études de l'emploi da França, em Paris, de fevereiro de 2000 a janeiro de 2002, reunidos no livro Organisation et intensité du travail (ASKENAZY et al., 2006). A partir desses trabalhos, selecionamos outros títulos por referência cruzada. Na literatura nacional foram escolhidos estudos a partir do campo da Saúde Coletiva/Saúde do Trabalhador, dado o nosso interesse em demarcar a particularidade da intensificação do trabalho e saúde na problemática da determinação social do processo saúde-doença dos trabalhadores no Brasil.

O desenvolvimento do estudo está organizado da seguinte forma: apresentamos um panorama do debate da intensificação do trabalho e saúde dos trabalhadores. Em seguida, analisamos a intensificação do trabalho considerando o processo de trabalho capitalista em seu conjunto, como uma unidade entre a produção imediata e a circulação do capital, com destaque para algumas de suas características contemporâneas. Na seção seguinte, discutimos a intensificação do trabalho na determinação social do processo saúde-doença dos trabalhadores, problematizando alguns limites da abordagem desgaste-reprodução. Por último, nas considerações finais, apresentamos uma síntese da definição conceitual para intensificação do trabalho e saúde do trabalhador.

\section{Um panorama do debate da intensifica- ção do trabalho e saúde dos trabalha- dores}

Um primeiro aspecto envolvido na definição da intensificação do trabalho é a necessidade de sua diferenciação da produtividade do trabalho, da intensidade do trabalho e do prolongamento do trabalho.

De acordo com Barisi (2006), a produtividade representa a capacidade de um determinado trabalho, dotado de intensidade definida, produzir uma quantidade de valor de uso em uma unidade de tempo. Intensidade do trabalho corresponde ao dispêndio de 
energia física, mental e psíquica do trabalhador pela realização da atividade em dada unidade de tempo. Para esse mesmo autor, intensificação do trabalho consiste no aumento da intensidade do trabalho, um entendimento comum a outros autores (DAL ROSSO, 2008; FERNEX, 1998).

A definição de intensificação como aumento da intensidade do trabalho é sintetizada por Dal Rosso (2008, p. 197) pela expressão "mais trabalho”. O autor invoca Marx (1984a) e argumenta que com a intensificação se obtém uma maior quantidade e/ou uma melhor qualidade dos resultados do trabalho com maior dispêndio de energia do trabalhador no mesmo tempo. Diferentemente, no aumento da produtividade se obtém mais resultados do trabalho com igual dispêndio de energia, no mesmo tempo, e no prolongamento da jornada de trabalho se produzem mais resultados do trabalho com maior dispêndio de energia decorrente da extensão da jornada.

Contudo, para Marx (1984a), "mais trabalho" significa mais-valia e representa o trabalho não pago apropriado pelos capitalistas no processo de produção independentemente das modalidades de sua obtenção, a saber: intensificação, produtividade ou prolongamento. Quer dizer, “mais trabalho” representa a característica comum ao processo de exploração do trabalhador no capitalismo e, portanto, não assinala a particularidade da intensificação nesse processo.

Definida como aumento do grau de intensidade do trabalho e como maior dispêndio de energia, a intensificação é caracterizada na literatura como um fenômeno puramente biológico ou biopsíquico, então pressuposto em todas as épocas sociais. Perde-se, assim, a dimensão histórica e a forma social particular, tanto do processo de exploração do trabalhador pelo capital e, nesse, da intensificação, quanto do processo saúdedoença dos trabalhadores, assim como a determinação social e histórica do segundo pelo primeiro.

Por conseguinte, isoladamente, a análise quantitativa é insuficiente para caracterização da intensificação do trabalho. Para Davezies (2007) e Hatzfeld (2004), o foco principal da análise deve se dirigir às transformações qualitativas do trabalho. Segundo Davezies (2007), o processo de intensificação do trabalho tende a reduzir a capacidade de o trabalhador manter todos os critérios relativos à qualidade do produto/serviço e à qualidade do trabalho em termos do desempenho profissional: de um lado, pode aumentar o risco de acidentes; de outro, pode afetar a identidade do trabalhador manifesto em sentimento de desgosto ou fracasso pessoal com risco para desencadear adoecimento.

Hatzfeld (2004) assinala tendências conflitantes quanto à carga de trabalho: as melhorias das condições ergonômicas reduziram o esforço muscular; entretanto, a diminuição do tempo de ciclo (o tempo para realização de uma ou mais operações em um dado posto de trabalho) aumentou o constrangimento para o trabalhador ganhar tempo para si pela autointensificação. O mais importante, ressalta Hatzfeld (2004), é o processo de decomposição cada vez mais refinado de cada tarefa (de suas operações, ações e gestos elementares) alcançado pela gerência ao expropriar/apropriar o "saber prático” do trabalhador, isto é, as capacidades físicas, psíquicas e intelectuais do trabalhador. Expropriação/apropriação é entendida como processo contínuo de assimilação do aprendizado coletivo dos trabalhadores pela gerência para vencer a resistência e obter a mobilização operária no processo de trabalho. É esse processo que permite reduzir o tempo de ciclo, fragmentar as operações e ampliar o trabalho repetitivo.

Além disso, a intensificação do trabalho também é pensada como referência a uma diversidade de elementos do processo de trabalho, tais como: a reorganização do tempo de trabalho (QUÉINNEC; BARTHE; VERDIER, 2000), o ritmo de trabalho (GOLLAC; VOLKOFF, 2007), as exigências de polivalência (GORGEU; MATHIEU; PIALOUX, 2006), a gestão por performance (desempenho) do trabalhador (BÁRTOLI; ROCCA, 2006). Esses aspectos serão retomados na próxima seção, inseridos na discussão e caracterização da intensificação do trabalho como dimensão particular do processo de exploração e expropriação do saber do trabalhador.

No que se refere à saúde do trabalhador, uma acepção positiva para o trabalho intenso aparece em Clot (2006, p. 315): “[...] um trabalho mais 'intenso', fonte de investimentos psíquicos renovados, de reflexão, mobilizador e produtor de sentido é frequentemente um recurso para a saúde”. No entanto, mesmo o autoinvestimento gratificante do trabalhador pode compreender um sofrimento mental. O próprio Clot (2006, p. 317) apreende essa situação ao indicar uma dissociação crescente entre a "intensificação do real do trabalho" e a "intensificação do trabalho realizado". Trata-se da distinção pela clínica da atividade entre "real da atividade" e "atividade realizada". No âmbito da primeira se encontra a atividade não realizada, restringida ou cerceada, que não desaparece da perspectiva do trabalhador, pois requisita uma intensa mobilização psíquica que pode ocasionar adoecimento.

A acepção de trabalho intenso como fonte de sofrimento e agravos à saúde dos trabalhadores é predominante na literatura. Davezies (2007, p. 32) se refere a um "tripé sintomático da intensificação do trabalho": a) a impossibilidade de manter um trabalho de boa qualidade; b) o assédio moral ou os conflitos entre os próprios trabalhadores; e c) os múltiplos danos à saúde (acidentes, a invasão do trabalho na vida pessoal, Lesões por Esforços Repetitivos - LER e os transtornos psíquicos). 
Mais recentemente, o estudo da intensificação parece se dirigir à temática das penosidades no trabalho. Segundo Linhart (2011), a penosidade emerge da impossibilidade de o trabalhador lidar e acompanhar as seguidas evoluções que redefinem os contextos de trabalho. Para os trabalhadores, as mudanças mantêm um estado de insegurança e de dependência da empresa e obstruem a possibilidade para vivenciar reflexivamente suas experiências no trabalho. Trata-se da tentativa empreendida pela gerência de evitar que se reconstituam coletivos próprios dos trabalhadores, potencial para ações de resistência e de contestação dos assalariados.

No Brasil, pode-se dizer que, a rigor, intensificação do trabalho e saúde ainda não constitui um objeto de pesquisa na Saúde Coletiva/Saúde do Trabalhador, muito embora alguns de seus aspectos apareçam entre os resultados de estudos nessa área.

O intenso ritmo de trabalho é o aspecto mais destacado pelos estudos entre os trabalhadores da indústria, especialmente por sua associação aos distúrbios músculo-esqueléticos decorrentes da situação de trabalho com altas demandas psicológicas e baixo controle (FERNANDES; ASSUNÇÃO; CARVALHO, 2010). No corte mecanizado da cana-de-açúcar, segundo Scopinho et al. (1999), o intenso ritmo de trabalho e as longas jornadas aparecem combinados ao trabalho noturno e em turno de revezamento associados às queixas de doenças relacionadas ao sistema cardiovascular e gastrointestinal, como também aos acidentes de trabalho de maior gravidade. No corte manual, o pagamento por produção está na determinação das mortes por excesso de trabalho dos cortadores de cana do Complexo Agroindustrial Canavieiro (ALVES, 2006).

Entre os professores, segundo Assunção e Oliveira (2009), o trabalho intenso conforma um sofrimento relacionado a um conflito entre as expectativas por fazer bem o trabalho e as exigências de regras que restringem o tempo, aumentam o volume e a sobreposição de tarefas, além de sua maior complexidade. Esse contexto "[...] teria levado [o professor] a ultrapassar ou a deixar de reconhecer o seu próprio limite" (ASSUNÇÃO; OLIVEIRA, 2009, p. 363) e pode explicar o cansaço físico, vocal e mental do docente e o afastamento por doença, especialmente a alta prevalência de transtornos psíquicos.

Da pesquisa de Melo (2007) entre os trabalhadores de serviços de tecnologias da informação e comunicação, algumas dimensões da intensificação do trabalho relacionada ao desgaste mental aparecem como achados e não como ponto de partida, tais como: o aumento do ritmo de trabalho, a exigência de disponibilidade e a realização simultânea de várias atividades implicadas na ampliação da jornada. A força desses resultados faz a autora ressaltar a relevância em tratar a intensificação como objeto de pesquisa na Saúde do Trabalhador, isto é, como "[...] a questão que se deveria inquirir com maior consistência, especialmente do ponto de vista dos determinantes e condicionantes das relações trabalho-saúde e do desgaste mental” (MELO, 2007, p. 213-214).

Como vimos, no Brasil, a carência de estudos em que o tema da intensificação do trabalho e saúde aparece como objeto específico de investigação se opõe à abundância de estudos em que seus resultados se aproximam ou estão implicados a alguns de seus possíveis contornos. A questão é que esses resultados são tomados como dados quando se trata de problematizálos enquanto objeto de pesquisa.

Além disso, a dificuldade em tratar a intensificação do trabalho e saúde enquanto um objeto de estudo está justamente em sua complexidade: nenhum elemento do processo de trabalho parece escapar à intensificação. Tanto mais, pela pluralidade de problemas de saúde implicados na intensificação do trabalho. Portanto, abordar a intensificação do trabalho e saúde como um objeto de pesquisa estruturado requer sua delimitação conceitual, de modo a torná-lo compreensível à luz dos diferentes aspectos relacionados ao processo de trabalho e saúde.

\section{Intensificação do trabalho como di- mensão particular da exploração e da expropriação do saber do trabalhador}

Nesta seção vamos avançar na definição da particularidade da intensificação do trabalho implicada ao processo de trabalho capitalista. Intensificação pressupõe aumento da intensidade do trabalho mas sua definição não é redutível a esse aumento; o que se destaca é o processo pelo qual se obtém esse aumento em uma determinada situação concreta.

No capitalismo, o processo de trabalho representa o próprio processo de exploração do trabalho. Intensificação do trabalho constitui uma dimensão social particular da exploração, distinta da força produtiva (produtividade) e do prolongamento da jornada de trabalho. Com base em Marx (1984a, b), consideramos cada uma dessas modalidades em relação ao fundamento da exploração, a saber, a mais-valia. Os resultados do processo de trabalho são produtosvalor, esses possuem, além de utilidade social, valor e, além de valor, mais-valia. A mais-valia caracteriza o modo específico segundo o qual, no próprio processo de trabalho, o capitalista constrange o trabalhador e realiza o consumo produtivo de sua capacidade de trabalho de modo a gerar um valor maior do que o valor da força de trabalho. 
No prolongamento da jornada de trabalho, a extração e a ampliação da mais-valia decorrem da incorporação de um maior quantum de trabalho pelo aumento da grandeza extensiva da jornada expresso no aumento do produto-valor global. Na força produtiva aumentada, mantida a mesma jornada, o mesmo quantum de trabalho proporciona o aumento da mais-valia pela contração absoluta e relativa do valor da força de trabalho, isto é, do tempo de trabalho socialmente necessário para produção dos meios de subsistência para a reprodução do trabalhador. Aqui, uma parte maior da mais-valia é extraída do mesmo produtovalor global em razão da redução do valor da força de trabalho. Diferentemente, na intensificação do trabalho, o aumento da mais-valia resulta da obtenção de um maior quantum de trabalho no mesmo intervalo de tempo pela ampliação do produto-valor global e manutenção do valor absoluto da força de trabalho.

A intensificação representa uma dimensão particular da exploração relativa à grandeza intensiva do trabalho e assinala a tendência à redução da porosidade da jornada.

A metáfora da porosidade dá a ideia simultaneamente física/abstrata, e biopsíquica/concreta, de que a jornada de trabalho tem densidade, compreende continuidades/descontinuidades e também aberturas/fechamentos: por meio dos "poros" o trabalhador "respira na ação", no tempo em que trabalha, torna-o mais ou menos denso. (PINA; STOTZ, 2011, p. 171)

No entanto, diversas formas de aumentar a extração de mais-valia pela obtenção de um maior quantum de trabalho no mesmo intervalo de tempo seriam possíveis de se combinarem, constituírem e funcionarem. Esse é outro aspecto que limita a definição de intensificação do trabalho apenas como aumento da intensidade, pois não se pode deduzir o processo de seu funcionamento apenas por suas características formais.

Assim como fez Marx (1984b, p. 34), é necessário perguntar "como o trabalho é intensificado"? O autor caracterizou a intensificação no processo contraditório e histórico em que se desenvolve e se transforma a produção capitalista. A luta dos trabalhadores pela redução da jornada e a legislação fabril impeliram o capital a acelerar o desenvolvimento das forças produtivas e a intensificação do trabalho.

$\mathrm{O}$ aperfeiçoamento da maquinaria se desenvolve destruindo o antigo trabalho manufatureiro, bem como o trabalho artesanal. A intensificação emerge como um processo histórico correlato à superação do fundamento da divisão do trabalho manufatureiro, a saber, a expropriação técnica e social do conhecimento exclusivo do trabalhador no manejo de suas habilidades e ferramentas específicas, o que representava a dependência do capital em relação ao trabalhador coletivo combinado, constituído por muitos trabalhadores parciais. Trata-se, da instituição da dinâmica tendente a ampliar a subordinação do trabalhador pelas exigências de aprendizado/reaprendizado e de sua adaptação ao movimento contínuo e acelerado dos meios e dos métodos de produção.

A regulação social da jornada não impede a exploração do trabalhador pelo capital, mas impulsiona sua metamorfose. Isso sugere o entendimento da legislação do trabalho, simultaneamente, como obstáculo e como elemento motor da transformação do processo de exploração, na qual se insere a intensificação, sendo o segundo seu aspecto tendencialmente dominante.

Até aqui, a discussão da intensificação em relação à extração da mais-valia considerou apenas o processo de produção imediato. A seguir, a intensificação será considerada em relação à taxa de lucro (relação entre a massa de mais-valia e dado capital global) e o estudo amplia-se para o processo de trabalho de conjunto, ou seja, deve pressupor a unidade entre a produção imediata e a circulação do capital (MARX, 1984c).

Marx (1984c) mostrou como o movimento do capital se desenvolve de modo contraditório: de um lado, o aumento da força produtiva do trabalho impulsiona a elevação do grau de exploração do trabalhador e com isso da taxa média de lucro e, de outro, com a sucessiva reaplicação do capital, tende, de modo contrário, a influir na queda da taxa de lucro. Isso em razão da elevação da composição orgânica do capital, isto é, o aumento do capital constante (valor global dos meios de produção) relativamente ao capital variável (valor global da força de trabalho). E justamente o prolongamento e a intensificação do trabalho são modalidades que aumentam a exploração e atenuam os efeitos da tendência à queda da taxa de lucro.

Dessa perspectiva, esboçamos algumas práticas de intensificação do trabalho como dimensão particular da exploração e expropriação do saber do trabalhador nas condições históricas pós-crise dos anos 1970.

Historicamente, a redução da jornada esteve e ainda está acompanhada de injunções para intensificar o trabalho. Nas últimas décadas, os efeitos positivos da redução da jornada são questionados pela adoção de modalidades de flexibilização ou de fragmentação do tempo de trabalho (QUÉINNEC; BARTHE; VERDIER, 2000). Por exemplo, no Brasil, o instrumento legal da compensação de horas (conhecido como banco de horas) pelo período de 12 meses possibilitou promover o prolongamento da jornada e, simultaneamente, a intensificação do trabalho (PINA; STOTZ, 2011). Quer dizer, ao mesmo tempo em que representa uma dimensão particular da exploração relativa à grandeza extensiva do trabalho, portanto, distinta da intensificação, o prolongamento da jornada também pode ser considerado uma forma de intensificar o trabalho. 
Quéinnec, Barthe e Verdier (2000) também apontaram outras práticas de reorganização do tempo de trabalho implicadas ao processo de intensificação, dentre as quais: a extensão do número de horas por turno de trabalho (por exemplo, com a mudança de turma do trabalhador) e a dissociação dos tempos dos homens dos períodos de operação das máquinas, por meio da extensão da produção em tempo integral aos sábados, domingos e feriados e em horários noturnos. Nos dois casos, o prolongamento viabiliza a continuidade das operações sem interromper o fluxo produtivo e, com isso, mantém elevado o ritmo de trabalho pela redução ou eliminação dos intervalos ("poros") intra e interturnos na virada do turno de trabalho.

Entre as novas características da intensificação, Gollac e Volkoff (2007) destacam o crescimento do número de trabalhadores submetidos a elevado ritmo de trabalho pela combinação simultânea de exigência industrial, em que o ritmo de trabalho depende de um equipamento automático ou de normas ou de prazos de produção de, no máximo, um dia, e de exigência comercial, em que o ritmo de trabalho depende da demanda.

Os estudos de Pina (2012) e de Hatzfeld (2004), apoiados em dados empíricos, indicam que a caracterização do ritmo de trabalho como intenso independe da demanda. Contudo a combinação entre exigência industrial e exigência comercial pode agravar a intensificação do trabalho, uma vez que as flutuações da demanda também atuam na variação do grau em que se processa o intenso ritmo de trabalho, sendo decisivo observar o desenvolvimento concreto da acumulação capitalista. Como assinala Pina (2012), para o caso do processo de trabalho no setor de veículos pesados da indústria automobilística no Brasil, na última década, o crescimento da produção de commodities agrícolas e minerais e a expansão do crédito impulsionaram e, especialmente, alteraram o perfil da demanda na direção da maior participação dos modelos de caminhões pesados e superpesados. Isso acentuou o grau de intensificação do trabalho tanto pela ampliação do prolongamento da jornada, com dias adicionais de trabalho aos sábados, domingos e feriados, quanto pela maior frequência da fabricação e montagem de peças maiores, portanto, com exigências de maior esforço contra a gravidade e postura forçada em situação de constrangimento temporal.

Além disso, o estoque mínimo e o número reduzido de trabalhadores tornam o fluxo de produção mais tenso, com a redução do tempo de ciclo da produção/ circulação. Essa maior tensão é a base objetiva em que se processam práticas gerenciais de expropriação do conhecimento do trabalhador implicadas na redução do tempo de ciclo, por exemplo, por meio da interação entre os trabalhadores na forma do trabalho em equipe (CIPOLLA, 2005). De acordo com esse autor, parte das funções de supervisão dos trabalhadores, antes concentradas na gerência, emerge e se encontra disseminada no interior do próprio grupo, tais como: acompanhamento do sistema de metas (volume, qualidade, custos) e a gestão de folgas, férias ou outro tipo de absenteísmo. Tarefas de supervisão emanadas do grupo que confrontam a resistência do trabalhador individual e, ao mesmo tempo, solicitam sua mobilização de modo contínuo e intenso.

O fluxo tenso da produção também é a base material para a emergência do estresse como instrumento de administração das empresas. A administração por estresse, segundo Parker e Slaughter (1995), tem por objetivo assegurar a manutenção permanente da pressão em todos os pontos e momentos do processo de produção, para que os "problemas" do sistema produtivo tornem-se imediatamente visíveis para a gerência superior. Isso, além de tentar evitar ou reduzir as "folgas" que os trabalhadores conseguem criar para si na jornada, permite à gerência descobrir os pontos considerados "gargalos" e desenvolver mais rapidamente possíveis inovações, reduzir custos e perdas ao criar pressão adicional sobre os trabalhadores para sua correção.

Para Gorgeu, Mathieu e Pialoux (2006), o uso intensivo do trabalho se manifesta na exigência de "polivalência". Entretanto, na administração por estresse, em lugar de "polivalência", seria melhor falar em rotação ou revezamento de tarefas e postos de trabalho, assim mesmo, dentro de certos limites. A rotação é adotada como treinamento suficiente para reorganizar tarefas e postos, especialmente para dificultar o trabalhador a reter para si conhecimentos de seu posto. A rotação de tarefas se conecta ao uso intensivo da força de trabalho, na medida em que permite a mobilidade interna do trabalhador pelos setores da empresa.

A administração por estresse está integrada por uma gestão por performance (BÁRTOLI; ROCCA, 2006), a saber: a mobilização das competências, a gestão por objetivos e a avaliação do trabalhador. Como instrumento gerencial, o estresse solicita a mobilização do trabalhador para disponibilizar sua experiência. Esse procedimento é significativo para a avaliação das competências do trabalhador, centrada mais nos meios por ele mobilizados para realizar as atividades do que propriamente nos resultados.

Pode-se dizer que a administração por estresse atualiza a "administração científica" ao enfrentar uma questão central à prática gerencial, a saber: expropriar o conhecimento do trabalhador e empreender sua ativa mobilização no processo de trabalho. Para Taylor (1966, p. 134-36), isso representaria a "publicização" do saber-fazer do trabalhador e a conquista pela gerência do "empenho criador" e da "verdadeira 
iniciativa do operário", subsumidos na base técnica e organizacional da empresa.

Entretanto, a mobilização subjetiva do trabalhador não é simples efeito derivado da cadeia automática, nem tampouco dos métodos de administração por estresse. Trata-se, mais amplamente, das condições históricas, políticas, jurídicas e ideológicas da correlação de forças entre capital e trabalho, que se expressam concretamente na empresa. Em consequência, pode-se pensar situações nas quais o trabalhador, individual ou coletivamente, confronta a intensificação do trabalho.

Para Linhart (2007), nas condições históricas da empresa taylorista-fordista, a existência de coletivos informais de trabalhadores possibilitou a abertura para a ajuda mútua, a solidariedade, o compartilhamento de valores com conotação sindical, política ou profissional vinculados a uma experiência comum. Esses coletivos escapavam das prescrições e estabeleceram outras regras e formas de fazer. Segundo Linhart (2007, p. 102), isso caracterizou uma "participação paradoxal" dos trabalhadores, uma vez que esses coletivos viabilizavam a eficácia produtiva e, ao mesmo tempo, mantinham uma desconfiança da empresa.

Diferentemente, a administração por estresse empreende um esforço na direção da "[...] prescrição da subjetividade individual e coletiva dos assalariados" (LINHART, 2007, p. 121), na tentativa de suprimir dos trabalhadores o direito ao distanciamento em relação à racionalidade, à norma e à cultura da empresa. $\mathrm{O}$ foco recai mais nos objetivos a atingir, nas exigências de disponibilidade e na mobilização das competências do trabalhador do que na prescrição da tarefa (BÁRTOLI; ROCCA, 2006).

Assim, a intensificação do trabalho se caracteriza pelo sistemático confronto às iniciativas individuais e coletivas dos trabalhadores que, de algum modo, representem uma base de resistência efetiva ou potencial à adesão do trabalhador na empresa. Isso tende a despojar a proteção dos danos à saúde e, principalmente, a despojar a capacidade de determinado coletivo de trabalhadores para questionar a determinação social dos agravos à sua saúde.

\section{Intensificação do trabalho na determi- nação do processo saúde-doença dos trabalhadores}

Como vimos, o processo de intensificação do trabalho corresponde a uma dimensão particular da exploração do trabalhador, processo contraditório e histórico de obtenção de um maior quantum de trabalho em dado período de tempo que se efetiva pela expropriação do conhecimento (experiência) do trabalhador no processo de trabalho. Nesta seção procuramos caracterizar o processo de intensificação do trabalho e saúde na problemática da determinação social do processo saúde-doença dos trabalhadores implicado no processo de trabalho (BREILH, 2010).

Comecemos pela contribuição de Laurell e Noriega (1989) ao estudar o processo de trabalho como um modo específico de se trabalhar e de se desgastar no âmbito da reprodução social de dada coletividade de trabalhadores. O conceito de desgaste está referido ao processo de exploração do trabalhador, por conseguinte podemos aproximar os sentidos de desgaste e intensificação do trabalho.

A abordagem do desgaste-reprodução denomina de carga de trabalho os elementos que "[...] interatuam dinamicamente entre si e com o corpo do trabalhador" (LAURELL; NORIEGA, 1989, p. 110) e sintetizam a mediação entre o processo de trabalho e o desgaste do trabalhador. Ainda segundo os autores, desgaste é “[...] entendido como a perda da capacidade potencial e/ ou efetiva corporal e psíquica" (LAURELL; NORIEGA, 1989, p. 110). O desgaste pode ou não se manifestar em patologia e não se refere necessariamente a processos irreversíveis.

Os elementos implicados no processo de intensificação do trabalho podem ser concebidos por meio da noção de exigências apresentada por Noriega (1993), com as ressalvas indicadas a seguir. Esse autor utiliza exigências para designar os elementos derivados da organização do trabalho e a noção de riscos para designar os elementos derivados dos objetos e dos meios de trabalho, ambas, em substituição à carga de trabalho.

Mas, ao estabelecer a distinção entre riscos e exigências, Noriega (1993) repõe o procedimento analítico de identificar e examinar isoladamente os elementos derivados da organização do trabalho e dos objetos e dos meios de trabalho, sem estabelecer suas implicações. Diferentemente dele, sem limitar sua referência à organização do trabalho e reinserir a noção de risco, preservamos o significado mais amplo de exigências, entendidas como os requerimentos impostos aos trabalhadores, derivados dos elementos do processo de trabalho de conjunto, particularmente da intensificação do trabalho, como caracterizados na seção anterior, a exemplo do ritmo de trabalho, do prolongamento da jornada e da administração por estresse.

Além disso, embora abandone a denominação carga de trabalho, em Noriega (1993) a noção de exigência ainda mantém o mesmo problema teóricometodológico presente em Laurell e Noriega (1989). Ou seja, especialmente no que se refere às cargas psíquicas, os autores admitem que

[...] se pode suportar altos ritmos de trabalho sem maiores problemas enquanto a tarefa permite a 
tomada de decisões, mas quando, pelo contrário, ela está esvaziada de um conteúdo significativo, torna-se estressante. (LAURELL; NORIEGA, 1989, p. 113-14)

Essa possibilidade corresponderia ao denominado "trabalho ativo" do modelo Demanda-Controle (D-C) (KARASEK; THEORELL, 1990), inclusive considerado por Garfield (1983) por sua associação negativa com as doenças coronarianas.

O modelo D-C emerge e se difunde como resposta à mobilização política dos trabalhadores, nos anos 1960-70, com questionamentos das relações entre trabalho e saúde. O modelo compreende duas dimensões básicas: demanda psicológica e controle, todavia concebidas, cada qual, de forma isolada uma da outra. Tal procedimento nubla a relação entre ambas e de ambas com o processo de trabalho de conjunto.

Pelo modelo D-C, quanto mais o trabalhador utiliza suas habilidades, tanto maior seria sua latitude de decisão (controle) no trabalho. Contudo, não necessariamente esses elementos caminham no mesmo sentido. $\mathrm{O}$ trabalho na linha de montagem, por exemplo, embora de baixa latitude de decisão, requer muita habilidade (LACOMBLEZ; VÉZINA, 2008). No trabalho em equipe, a gerência transfere ao grupo a decisão quanto à distribuição e à realização das tarefas. No entanto, ainda segundo Lacomblez e Vézina (2008), isso pode implicar em aumento das tarefas e dos constrangimentos para cada trabalhador do grupo e, assim, em maior estresse.

O "trabalho ativo" do modelo D-C pode muito bem retratar o perfil de trabalhador preconizado pela administração por estresse (PINA; STOTZ, 2011). Podemos dizer, com base em Breilh (2010), que esse modelo está situado no âmbito dos "determinantes sociais da saúde”, uma vez que sua estruturação repousa nos marcos teóricos da sociologia funcionalista, portanto, diferentemente da "determinação social da saúde", que tem seu fundamento nas classes sociais em luta, concretizadas nas relações de exploração/resistência dos trabalhadores nas formações sociais capitalistas.

Também aqui nos distanciamos da noção de trabalho alienado, definido por Garfield (1983) como a perda do controle do trabalhador em relação ao produto, ao processo de trabalho e aos demais trabalhadores, pois ela desconsidera o papel ativo das representações na prática dos indivíduos e das classes sociais. A mobilização do trabalhador na realização do trabalho se efetiva por meio de uma construção positiva e não se reduz ao constrangimento externo ou à ausência (ou presença) de controle.

Subjacente à noção de alienação, as representações do trabalhador são entendidas como mero reflexo da realidade, como ilusória ou como "falsa consciência". A reversão da alienação, um passo para a "verdadeira consciência”, se daria pelo aumento do controle do processo de trabalho pelo trabalhador, por meio de sua participação na empresa capitalista, considerada uma forma embrionária na linha evolutiva em direção ao socialismo (GARFIELD, 1983).

Para não limitar a discussão da intensificação do trabalho e saúde a uma eventual dimensão cognitiva sobre a falsa ou verdadeira representação da realidade pelo trabalhador, devemos adentrar o campo das ideologias. Com base em Toledo (2003), ideologia é definida pelos efeitos ou pelo papel ativo que as práticas sociais, conscientes ou não, dos indivíduos e dos agentes sociais em luta assumem na mobilização do trabalhador para legitimar ou questionar a exploração/ expropriação do seu trabalho.

Portanto, estamos diante de um campo de disputas e de lutas, política, ideológica e sanitária, implicado na organização/desorganização dos coletivos próprios dos trabalhadores que integram os processos que determinam, respectivamente, seu perfil protetor e seu perfil destrutivo de saúde.

Isso porque o processo de intensificação do trabalho e saúde dos trabalhadores põe em destaque, de acordo com Berlinguer (1988), a doença como um sinal, individual e coletivo, ora reprimido ora ignorado ora distorcido ou, ainda, ora parcialmente reconhecido. Para esse autor, a debilidade da ação coletiva contribui para ocultar e distorcer o sinal da doença. O ocultamento do sinal é favorecido por relações políticas, jurídicas e pelo precário domínio do conhecimento sobre determinado processo de adoecimento entre os trabalhadores. A distorção do sinal se manifesta quando a doença não pode mais ser ocultada por sua gravidade, frequência e simultaneidade dos casos e, por isso, abre-se um período de atribuir-lhe causas estranhas às situações de trabalho ou a sua determinação social.

Mais amplamente, não apenas as doenças como também os diversos problemas de saúde dos trabalhadores constituem processo de desgaste, um conceito integrador para o campo da saúde mental e trabalho (SELIGMANN-SILVA, 1994). Para essa autora, o desgaste do trabalhador compreenderia três dimensões: a primeira, em termos orgânicos, decorrente dos acidentes de trabalho ou da ação de substâncias tóxicas; uma segunda, pela fadiga crônica; a terceira, pelo desgaste da esperança, que afeta a identidade do trabalhador, atinge seus valores e crenças e pode ferir sua dignidade.

Cabe salientar que a identidade do trabalhador deve ser considerada no âmbito da história: projetos, valores e crenças são passíveis de orientar a vida do trabalhador, por exemplo, na direção de sua identificação afetiva com a empresa e podem servir para legitimar práticas desencadeadoras de danos à sua saúde. Portanto, o questionamento coletivo de valores e crenças relativos à racionalidade da empresa pode assumir uma conotação distinta do desgaste 
da esperança, pois pode permitir aos trabalhadores considerarem o contexto de trabalho pela maior proteção à saúde (PINA, 2012).

Além disso, persiste a dificuldade relacionada à carência de indicadores para captar as manifestações do desgaste que se antecipem ao dano à saúde, uma vez que, na maioria das vezes, o desgaste é inespecífico e não se expressa de forma direta. Na tentativa de suprir essa dificuldade, recorremos à noção de sofrimento difuso, de acordo com Fonseca (2007), expresso por meio de queixas inespecíficas e sintomas bastante variados quanto à forma, magnitude, tempo e espaço em que se manifestam e são percebidos pelos trabalhadores, mas dificilmente enquadradas pela nosologia da clínica médica ou pela classificação psiquiátrica clássica.

Fonseca (2007) identifica outras nomeações que traduzem ideias semelhantes ao sofrimento difuso, em especial os chamados "transtornos mentais comuns" e o "código dos nervos". Os "transtornos mentais comuns" podem reunir múltiplos sintomas, tais como: insônia, irritabilidade, nervosismo, dores de cabeça, fadiga, esquecimento, falta de concentração. No "código dos nervos" as fronteiras entre corpo e mente são mais difusas e não estão bem definidas. As perturbações e as queixas dos trabalhadores corresponderiam a uma representação simultânea de sintomas físicos e não físicos.

Assim, ressaltamos a relevância de se refletir sobre o modo como os trabalhadores percebem o processo de intensificação do trabalho e suas implicações na saúde. As categorias de pensamento dos trabalhadores, segundo Lopes (1978), colocam em aberto algumas possibilidades: maior adesão ao discurso gerencial, formas abertas de confronto contra o capital e as que expressam formas ambíguas entre adesão e resistência, essa última predominante sobre as anteriores.

Trata-se de outra importante questão teóricometodológica, qual seja: o lugar da experiência operária na investigação. Apesar da experiência dos trabalhadores, segundo Laurell e Noriega (1989, p. 310), constituir uma fonte de conhecimento válida para construção do perfil patológico da coletividade de trabalhadores, os autores dão um passo atrás em relação ao Modelo Operário Italiano quando afirmam ser "[...] útil completá-la e reforçá-la [por meio de] uma comprovação de cunho científico tradicional, ou seja, no caso da saúde, quantitativa”. A validade e o reconhecimento da experiência operária ficam subordinados à lógica e ao referencial da "ciência", ou melhor, das teorias e métodos dominantes nesse campo.

A questão é bem mais ampla e não se reduz à denominação similar dos agravos à saúde dos trabalhadores empreendida pelas teorias dominantes sobre trabalho e saúde e pela experiência dos trabalhadores. Como ilustra Sato (1996), ao estabelecer as diferenças entre o que a literatura e o conhecimento dos trabalhadores identificam como trabalho penoso:
[...] embora ambos focalizem os mesmos tipos de problemas de saúde - incômodo, sofrimento e es- forço -, no caso do conhecimento do trabalhador, o que nucleia o conceito, ou seja, o cerne do proble- ma, é o controle, que remete justamente à relação dos trabalhadores com os contextos de trabalho, não se reduzindo a penosidade apenas à presença desses problemas e sim à condição de sujeito na re- lação de trabalho, onde o incômodo, o sofrimento e o esforço estão presentes. (SATO, 1996, p. 492)

Devido às implicações da noção de controle na literatura, como apontada acima na referência ao modelo D-C, o que a autora nomeia como "controle" ou a "condição de sujeito" seria mais pertinente designar como a capacidade coletiva do trabalhador para proteger sua saúde e, principalmente, para questionar as condições de determinação dos problemas e dos agravos à saúde. Também consideramos que a penosidade precisa ser pensada na dimensão do coletivo, inclusive quando se refere à ação individual. Como assinala Clot (2010), a perda, a ausência ou o enfraquecimento da dimensão coletiva na ação individual pode ser o fundamento da maioria das experiências de penosidade no trabalho atualmente suportadas pelos trabalhadores.

Essas ponderações permitem entender a complexidade da intensificação do trabalho e saúde do trabalhador como objeto de estudo na Saúde Coletiva/Saúde do Trabalhador, a saber, não reduzi-lo à identificação de resultados em termos de desgaste, fadiga, acidentes ou doenças produzidas pela intensificação do trabalho. Por conseguinte, ressaltamos dois aspectos para o estudo da intensificação do trabalho e saúde do trabalhador: o primeiro, as práticas de exploração e expropriação do saber (experiência), concretizadas em exigências de intensificação do trabalho, confrontam a capacidade coletiva do trabalhador para agir em direção contrária à racionalidade, à cultura e ao poder da gestão na empresa. Cabe, portanto, observar essa dinâmica, sobretudo a percepção, mais ou menos difusa, de perda, enfraquecimento ou ausência do coletivo, dadas suas implicações para os problemas e agravos à saúde. O segundo aspecto a observar é a produção de um tipo de desgaste mental (que mereceria talvez uma denominação específica) devido à própria percepção de perda, enfraquecimento ou ausência do coletivo. Ou seja, a percepção da impotência para enfrentar as exigências gerenciais, por si só, e não apenas suas consequências deletérias 
à saúde, está a desencadear múltiplas manifestações de sofrimento difuso.

\section{Considerações finais}

Neste estudo propusemos elaborar uma definição conceitual para o processo intensificação do trabalho e saúde do trabalhador enquanto objeto de estudo no campo da Saúde Coletiva, especificamente na área de Saúde do Trabalhador. Vimos que intensificação do trabalho e saúde do trabalhador como objeto de estudo está demarcado por sua complexidade: de um lado, nenhum elemento do processo de trabalho parece escapar à intensificação do trabalho e, de outro, pela pluralidade de problemas e agravos à saúde implicados na intensificação do trabalho.

No desenvolvimento do estudo situamos a problemática da intensificação do trabalho e saúde do trabalhador no ponto central da determinação social do processo saúde-doença dos trabalhadores implicado ao processo de trabalho. De modo sintético, intensificação do trabalho é entendida como uma dimensão social particular da exploração do trabalhador, resultado e processo histórico de obtenção de um maior quantum de trabalho por unidade de tempo, que se efetiva pela expropriação do conhecimento técnico e social do trabalhador no processo de trabalho. Tal conhecimento é condição básica de proteção da saúde dos trabalhadores. Conceitualmente, o objeto intensificação do trabalho e saúde do trabalhador pode ser definido e estudado nas práticas específicas de exploração/expropriação tendentes a enfraquecer a capacidade coletiva do trabalhador, para proteger sua saúde e, principalmente, para questionar as determinações dos problemas e dos agravos à sua saúde.

Acreditamos que este estudo contribui para o conhecimento científico do processo de trabalho e saúde por estabelecer a conexão lógica e histórica da intensificação do trabalho e saúde do trabalhador, inclusive por trazer subsídios à elaboração de futuras pesquisas empíricas para abordar essa temática a partir da percepção dos trabalhadores.

\section{Contribuições de autoria}

PINA, J. A.: responsável pela definição do marco teórico, planejamento, realização da pesquisa e pela redação do artigo. STOTZ, E. N.: participou da orientação geral da pesquisa, contribuiu na estruturação e na revisão do manuscrito.

\section{Referências}

ALVES, F. Por que morrem os cortadores de cana? Saúde e Sociedade, São Paulo, v. 15, n. 3, p. 90-98, 2006. http://dx.doi.org/10.1590/S010412902006000300008.

ASKENAZY, P., et al. (Orgs.). Organisation et intensité du travail. Toulouse: Octarès, 2006.

ASSUNÇÃO, A. A.; OLIVEIRA, D. A. Intensificação do trabalho e saúde dos professores. Educação \& Sociedade, Campinas, v. 30, n. 107, p. 349-372, 2009. http://dx.doi.org/10.1590/S0101-73302009000200003.

BARISI, G. L'intensification du travail, entre économie de temps et économie des échanges. In: ASKENAZY, P. et al. (Orgs.). Organisation et intensité du travail. Toulouse: Octarès, 2006. p. 11-20.

BÁRTOLI, M.; ROCCA, M. Gestion par objectifs et réquisition de compétences: vers de nouvelles sources d'intensification du travail? In: ASKENAZY, P. et al. (Orgs.). Organisation et intensité du travail. Toulouse: Octarès, 2006. p. 21-28.

BERLINGUER, G. A doença. São Paulo: Hucitec, 1988.

BREILH, J. Las tres 'S' de la determinación de la vida: 10 tesis hacia una visión crítica de la determinación social de la vida y la salud. In: NOGUEIRA, R. P. (Org.). Determinação social da saúde e reforma sanitária. Rio de Janeiro: Centro Brasileiro de Estudos de Saúde, 2010. p. 87-125. Disponível em: <http:// www.cebes.org.br/media/File/Determinacao.pdf $>$. Acesso em: 20 mai. 2013.

CIPOLLA, F. P. Trabalho em equipe como forma da subsunção real. Estudos Econômicos, São Paulo, v. 35, n. 1, p. 203-232, 2005.

CLOT, Y. Trabalho e poder de agir. Belo Horizonte: FabreFactum, 2010.

CLOT, Y. Une intensification du travail peut-elle en cacher une autre? In: ASKENAZY, P. et al. (Orgs.). Organisation et intensité du travail. Toulouse: Octarès, 2006. p. 313-317.

DAL ROSSO, S. Mais trabalho: a intensificação do labor na sociedade contemporânea. São Paulo: Boitempo, 2008.

DAVEZIES, P. Intensification. Danger: le travail rétréci. Santé \& Travail, Paris, v. 57, p. 30-33, 2007.

FERNANDES, R. C.; ASSUNÇÃO, A. Á.; CARVALHO, F. M. Tarefas repetitivas sob pressão temporal: 
os distúrbios musculoesqueléticos e o trabalho industrial. Ciência \& saúde coletiva, Rio de Janeiro, v. 15, n. 3, p. 931-942, 2010. http://dx.doi.org/10.1590/ S1413-81232010000300037. PMid:20464207

FERNEX, A. Intensité du travail, définition, mesure, évolutions: premiers repérages. Etudes et Recherche, Paris, n. 169, 1998.

FONSECA, M. L. G. Sofrimento difuso, transtornos mentais comuns e problemas de nervos: uma revisão bibliográfica a respeito das expressões de mal-estar nas classes populares. 2007. 153 f. Dissertação. (Mestrado em Saúde Pública)-Escola Nacional de Saúde Pública Sergio Arouca, Fundação Oswaldo Cruz, Rio de Janeiro, 2007.

GARFIELD, J. O trabalho alienado, stress e doença coronariana. In: NUNES, E. (Org.). Medicina social: aspectos históricos e teóricos. São Paulo: Editora Global, 1983. p. 158-175.

GOLLAC, M.; VOLKOFF, S. Les conditions de travail. Paris: Éditions La Découverte, 2007.

GORGEU, A.; MATHIEU, R.; PIALOUX, M. Polyvalence, polycompétence ouvrières et intensfication du travail: l'exemple de l'industrie automobile. In: ASKENAZY, P. et al. (Orgs.).

Organisation et intensité du travail. Toulouse: Octarès, 2006. p. 53-61.

KARASEK, R.; THEORELL, T. Healthy work: stress, productivity, and the reconstruction of working life. New York: Basic Books, 1990.

HATZFELD, N. L'intensification du travail en débat. Ethnographie et histoire aux chaînes de PeugeotSochaux. Sociologie du Travail, Paris, v. 46, n. 3, p. 291-307, 2004. http://dx.doi.org/10.1016/j. soctra.2004.06.001.

LACOMBLEZ, M.; VÉZINA, N. Karasek. Laboreal, Scientrier, v. IV, n. 2, p. 114-117, 2008.

LAURELL, A. C.; NORIEGA, M. Processo de produção e saúde: trabalho e desgaste operário. São Paulo: Hucitec, 1989.

LINHART, D. Entrevista: Danièle Linhart. Trabalho, Educação e Saúde, Rio de Janeiro, v. 9, n. 1, p. 149160, 2011.

LINHART, D. A desmedida do Capital. Rio de Janeiro: Boitempo, 2007.

LOPES, J. S. L. O vapor do diabo: trabalho e os operários do açúcar. 2. ed. Rio de Janeiro: Paz e Terra, 1978.

MARX, K. O Capital: crítica da economia política. L. I, T I. São Paulo: Abril Cultural, 1984a.

MARX, K. O Capital: crítica da economia política. L. I, T II. São Paulo: Abril Cultural, 1984b.
MARX, K. O Capital: crítica da economia política. L. III, T. I. São Paulo: Abril Cultural, 1984c.

MELO, A. I. S. C. Trabalho e saúde: um estudo entre trabalhadores de serviços de tecnologias da informação. 2007. 288 f. Tese (Doutorado em Saúde Pública)-Escola Nacional de Saúde Pública Sergio Arouca, Fundação Oswaldo Cruz, Rio de Janeiro, 2007.

NORIEGA, M. Organización laboral, exigencias y enfermedad. In: LAURELL, A. C. (Org.). Para la Investigación Sobre la Salud de los Trabajadores, Serie PALTEX 3. Washington: Organización Panamericana de la Salud, 1993. p. 167-187.

PARKER, M.; SLAUGHTER, J. Unions and management by stress. In: BABSON, S. (Org.). Lean work: empowerment and exploitation in the global auto industry. Detroit: Wayne State University Press, 1995. p. 41-53.

PINA, J. A. Intensificação do trabalho e saúde dos trabalhadores na indústria automobilística: estudo de caso na Mercedes Benz do Brasil, São Bernardo do Campo. 2012. 367 f. Tese (Doutorado em Saúde Pública)-Escola Nacional de Saúde Pública Sergio Arouca, Fundação Oswaldo Cruz, Rio de Janeiro, 2012.

PINA, J. A.; STOTZ, E. N. Participação nos lucros ou resultados e banco de horas: intensidade do trabalho e desgaste operário. Revista Brasileira de Saúde Ocupacional, São Paulo, v. 36, n. 123, p. 162-176, 2011.

QUÉINNEC, Y.; BARTHE, B.; VERDIER, F. Réduction du temps de travail et organisation de l'activité de travail: des rapports ambigus et complexes. In: TREMBLAY, D. G.; TERSSAC, G. (Orgs.). Où va le temps de travail? Toulouse: Octarès, 2000. p. 133-142.

SATO, L. As implicações do conhecimento prático para a vigilância em saúde do trabalhador. Cadernos de Saúde Pública, Rio de Janeiro, v. 12, n. 4, p. 489-495, 1996. http://dx.doi.org/10.1590/S0102311X1996000400007. PMid:10904352

SCOPINHO, R. A., et al. Novas tecnologias e saúde do trabalhador: a mecanização do corte da cana-deaçúcar. Cadernos de Saúde Pública, Rio de Janeiro, v. 15, n. 1, p. 147-162, 1999.

SELIGMANN-SILVA, E. Desgaste mental no trabalho dominado. Rio de Janeiro: Editora UFRJ/Cortez, 1994.

TAYLOR, F. W. Princípios de administração científica. 6. ed. São Paulo: Editora Atlas, 1966.

TOLEDO, C. N. Ideologia em Marx. In: CICLO DE PALESTRAS MARX E O MARXISMO EM DOZE LIÇÕES, 2003, São Paulo. Separata mimeo... São Paulo: Colégio São Paulo, 2003. 21 p. 